\title{
Redeployed: Reflections from the Once Epicenter of COVID-19
}

\author{
Kelsey B. Bryant, MD, MPH, MS๑ \\ Division of General Medicine, Columbia University Medical Center, New York, NY, USA.
}

J Gen Intern Med 36(5):1432-3

DOI: $10.1007 / \mathrm{s} 11606-021-06637-4$

(c) Society of General Internal Medicine 2021

$I_{\mathrm{c}}$ opened my closet door and stared at the professional clothing hanging before me. My old scrubs were buried somewhere, along with my pager that still lay dead on my closet floor. My laundry pile no longer included streaks of unbecoming seafoam green - the color of my residency scrubs. The absence of scrubs and fleeces adorned with my institution's logo had been a symbol of a new chapter in my career. As I dug through items in bags bound for donation in search of that vintage seafoam green, I was filled with unease. I did not know at the time, but this was the peak of the COVID-19 outbreak in New York City.

Weeks before, my inpatient colleagues had seen the tsunami building from the shore (read: emergency department entrance), while I watched coverage of the impending wave from the comfort of home between televisits. I knew my call would come, and while I waited, I felt ineffective, telling many patients what our plan would be if only we could safely carry it out. I was distracted thinking about all the ways my patients would suffer physically, emotionally, and financially as this wave continued to build with unknowable potential of devastation. In some ways I was relieved when my redeployment call came even though it meant risking infection myself. At least this way I would know my contribution to this crisis was tangible.

Lessons from residency I had not been required to call upon in some time as an almost exclusively outpatient physician came flooding back. It did not take long for it to be clear that my near decade of medical training made me more than adequate to fill this role. Clinical reasoning and evidencebased practice were important, but these details were not causing me to lose sleep. Patients wailing "I don't want to die" after I informed them of their positive COVID-19 tests were. While I tried to sleep, difficult phone conversations played on a loop in my head. I spoke to many families providing guarded reassurance that their loved one was stable, only to learn they had fallen off the proverbial COVID-19 cliff

Received December 15, 2020

Accepted January 24, 2021

Published online February 23, 2021 hours later. As it turns out, I was misguided to worry about my medical knowledge. What lay in question was my resilience to weather so much human suffering.

A core lesson from my residency training resurfaced while caring for admitted COVID-19 patients: the value of a dignified, peaceful death.

While death is often an unexpected tragedy, as I experienced in my own family with the sudden loss of my father while I was in college, my encounters as a trainee taught me that loved ones do not have to be introduced to grief the way I was. I often felt like my own history of loss shielded me from the sadness that comes with losing patients. I was not afraid to sit with family members and gently guide them through what to expect regarding a critically ill loved one. In these difficult situations, I told many junior residents and students that, whether they liked it or not, they were part of these families' grieving processes and should act accordingly in all their interactions. Our faces would be remembered. Accompanying kindness and empathy-or lack thereof-becomes a part of someone's grief story. COVID-19 robbed so many people of peaceful, intimate final moments with their loved ones while I dissolved into a faceless name over the phone delivering often uncertain and sometimes disastrous news.

From hearing stifled sobs over the phone to watching a patient struggle to breathe, my ability to quote the most recent published findings regarding COVID-19 management was irrelevant. Finding a way for my patients who I knew would not survive hospitalization to die with dignity was now urgent. Prior to this crisis, end of life care almost always involved loved ones at the bedside. Now, in phone conversation after phone conversation, I walked someone I could not look in the eye through the dying process. Sometimes met with silence, other times met with detailed questions about debunked therapies in an attempt to find hope, my grief and theirs weighed on me. I did everything I could to help patients and families feel supported, but I will never know if I succeeded. My name and voice, rather than my face and presence, are now a part in so many stories of loss, whether I like it or not.

Now that I am back to my regular job, more or less, I am picking up the pieces of my patients' complex care that fell apart in the early days of this crisis. With lost 
wages and insurance coverage, many patients were unable to afford necessary medications. When I am finally able to make contact with them, I am relieved to find them alive. Most of my clinical notes now detail the emotional suffering experienced by my patients and how that is contributing to their presentation. I have numerous unsatisfying conversations about symptoms with unlucky long-haulers, having little to offer but an ear to listen.

I will carry a piece of this experience with me forever, just as I hold onto those lessons from residency that I now know were stepping-stones to becoming the physician I am today. I bore witness to unspeakable trauma, and in all of this, I recognize I fared just fine. A product of the unearned privilege I carry in this world, I kept my job, my health, and my home. I had the space to process my experience and return to primary care patients, many of whom were not afforded such luxuries. While a vaccine will stop the spread, it will not return the loss of life and livelihood experienced by so many. My role as an individual may be small, but I will use every tool at my disposal as I advocate for my patients to have the health they deserve not just in the aftermath but for as long as they trust me to care for them.

Acknowledgements: Thank you to Sarah Kalina, MOT, Francesca Sternfeld, LMSW, Courteney Daniel, Esq, and Stephanie K. Marks, $D O$, candidate for their comments on this piece and ongoing support.

Corresponding Author: Kelsey B. Bryant, MD, MPH, MS; Division of General Medicine, Columbia University Medical Center, New York, NY, USA (e-mail:kb2828@cumc.columbia.edu).

Publisher's Note: Springer Nature remains neutral with regard to jurisdictional claims in published maps and institutional affiliations. 